\title{
Factors determing range of motion post operatively in total knee arthroplasty
}

\author{
Hitesh Shukla1, Arvind Goregaonkar ${ }^{2}$, Jitesh Manghwani ${ }^{3, *}$, Rajesh ${ }^{4}$, Rajib Naskar ${ }^{5}$ \\ ${ }^{1}$ Senior Resident, Dept. of Orthopaedics, Baba Sahib Ambedkar Hospital, Mumbai, Maharashtra, ${ }^{2}$ Professor and HOD, ${ }^{5}$ Senior \\ Resident, Dept. of Orthopaedics, Lokmanya Tilak Municipal Medical College and General Hospital, Mumbai, Maharashtra, \\ ${ }^{3}$ Senior Registrar, Dept. of Orthopaedics, Seth GS Medical College \& Kem Hospital, Mumbai, Maharashtra, ${ }^{4}$ Lecturer, Dept. of \\ Orthopaedics, Government Medical College, Nagpur, Maharashtra, India
}

\section{Corresponding Author: Jitesh Manghwani}

Email: dr.jiteshm@gmail.com

\begin{abstract}
Objective: Patient satisfaction after total knee arthroplasty is dependent on post operative range of motion and pain. This study is an attempt to determine the influence of factors like age, sex, BMI, pre op flexion, Tibiofemoral angle on post operative range of motion.

Materials and Methods: The sample size was 94, of which 4 patients were lost in follow up. The patients included were ones with similar type of implant, primary cases, similar technique and surgeon. Demographics, pre op range of motion using goniometer and tibiofemoral angle on radiographs was determined. The cases were followed up regularly for 1 year and the range was noted.

Results: Factors like age, BMI, pre operative flexion, Tibiofemoral angle determine the amount of flexion post operatively. However factor like sex is not statistically significant. The $\mathrm{p}$ value for pre operative flexion and tibiofemoral angle is $<0.001$ with correlation co efficient of 0.86 and -0.58 respectively.

Conclusion: Proper patient counseling about the range of motion achievable post operatively balancing the factors affecting it is important for patient satisfaction.

Total knee arthroplasty, range of motion, pre op flexion, tibiofemoral angle.
\end{abstract}

Keywords: Total knee arthroplasty, Range of motion, Pre op flexion, Tibiofemoral angle.

\section{Introduction}

Over the period of time the level of education and the wish of staying physically independent has lead to an increase in the number of joint replacements and also in patients opting the same who are younger than 60 years. $^{1}$ The successful outcomes are primarily measured on a scale of pain relief and range of motion. $^{2-6}$ It is confirmed by multiple studies that amount of flexion needed for various activities is different and not the same. It is approximately 67 degrees is needed for the swing phase, 83 degrees for climbing stairs, 90 degrees for descending stairs, and 93 degrees for rising from a chair. ${ }^{7-9}$ The amount of postoperative flexion is not the same in all the cases. There have been studies confirming the increased range of motion post operatively, in knees with restricted range of motion preoperatively. However there have been studies showing that the range remains the same or even may worsen after the replacement. Different studies have tried to find the significance of different parameters affecting the post operative range of motion. These includes patient demographic factors like age, sex, BMI, pain, comorbidities, tibiofemoral angle, etiology of arthritis and some surgeon factors like choice of implant, physiotherapy protocols..$^{2-7,10-12}$ Our study aims to find such factors which contribute to the amount of flexion patient has post operatively and determining the common linking factors between the population having restricted flexion post operatively.

\section{Materials and Methods}

This study was prospective and retrospective. The study was done on a sample size of 94 . We lost 4 patients in follow up. Of the total 31 were males and 59 were females. The cases were analysed at the end of one year. Regular follow up was scheduled. The cases included in the study were primary cases undergoing fixed bearing, cruciate substituting type of design. The ones with etiology being osteoarthritis or rheumatoid arthritis only were included. The cases excluded were ones undergoing revisions, ones having complications postoperatively like infection, previously operated knee, different type of implant like high flexed, hinged. The cases included were ones who gave written informed consent.

Preoperatively the age, sex, BMI, comorbidities, range of motion, tibiofemoral angle were taken into account. All the cases were operated by the same surgeon after written informed consent. The cases were performed under local or general anesthesia using pneumatic tourniquet. The surgical technique in all the cases was similar, cemented implants, same type of implant (The implant company is not mentioned because the author avoids being a source of any form of publicity). All the cases had post operatively negative suction drain inserted for approximately 48 hours. The patients were under the cover of antibiotic prophylaxis. Postoperatively the patients underwent similar physiotherapy regimens. The patients were followed up for 1 year regularly to record the range of motion achieved. The flexion and extension was measured 
using a goniometer. Tibiofemoral angle was measured on $\mathrm{x}$ rays.

The data collected was analysed by STRATA software using pearson coefficient (normally distributed data) and spearmans coefficient (data not normally distributed).

\section{Results}

Age: The average flexion postoperatively of patients less than 60 years was 111.6 degrees and of those more than 60 years of age was 96.7 degrees. These results are statistically significant with a $\mathrm{p}$ value of $<0.001$. (unpaired ' $\mathrm{t}$ ' test)

Table 1: Relation between age and flexion postoperatively

\begin{tabular}{|l|c|c|c|}
\hline S. No. & Age & Flexion range post operatively & Mean flexion \\
\hline 1 & Less than 60 & $101.5-116.3$ & 111.6 \\
\hline 2 & More than 60 & $90.8-104.6$ & 96.7 \\
\hline
\end{tabular}

$\mathrm{P}$ value $<0.001 *$ by using unpaired ' $\mathrm{t}$ ' test * Significant

Sex: The average flexion in males postoperatively was 107.1 degrees and that in females was 101.4 degrees.

However this flexion is not statistically significant. (unpaired ' $\mathrm{t}$ ' test)

Table 2: Relation between sex and flexion postoperatively

\begin{tabular}{|l|c|c|c|}
\hline S. No. & Sex & Flexion range post operatively & Mean flexion \\
\hline 1 & Males & $98.5-112.5$ & 107.1 \\
\hline 2 & Females & $90.8-111.6$ & 101.4 \\
\hline
\end{tabular}

BMI: The average amount of flexion for patients with BMI less than 30 was 114.7 degrees while for patients with BMI more than 30 was 97.5 degrees. These values are statistically significant. (unpaired ' $t$ ' test)

Table 3: Relation between BMI and flexion postoperatively

\begin{tabular}{|l|c|c|c|}
\hline S. No. & BMI & Flexion range post operatively & Mean flexion \\
\hline 1 & Less than 30 & $101.5-120.3$ & 114.7 \\
\hline 2 & More than 30 & $90.8-112.5$ & 97.5 \\
\hline
\end{tabular}

$\mathrm{P}$ value $<0.001 *$ by using unpaired 't' test * Significant

Preop Flexion Range: The average amount of flexion for patients with flexion range less than 90 degrees was 74.2 degrees preoperatively. This increased to average 101.4 degrees. The average flexion increased from an average value of 99.4 degrees to 114.1 degrees post operatively. These values are statistically significant with $\mathrm{R}=0.86$ (Spearman Correlation as data is NOT normally distributed) and $\mathrm{P}$ value $<0.001$ by using Spearman correlation test.

Table 4: Relation between preoperative flexion and flexion postoperatively

\begin{tabular}{|l|c|c|c|c|}
\hline S. No. & Preop Flexion & Mean preop flexion & Flexion range post operatively & Mean flexion \\
\hline 1 & Less than 90 & 74.2 & $90.8-108.2$ & 101.4 \\
\hline 2 & More than 90 & 99.4 & $98.4-120.3$ & 114.1 \\
\hline
\end{tabular}

$\mathrm{P}$ value $<0.001 *$ by using Spearman correlation test $*$ Significant

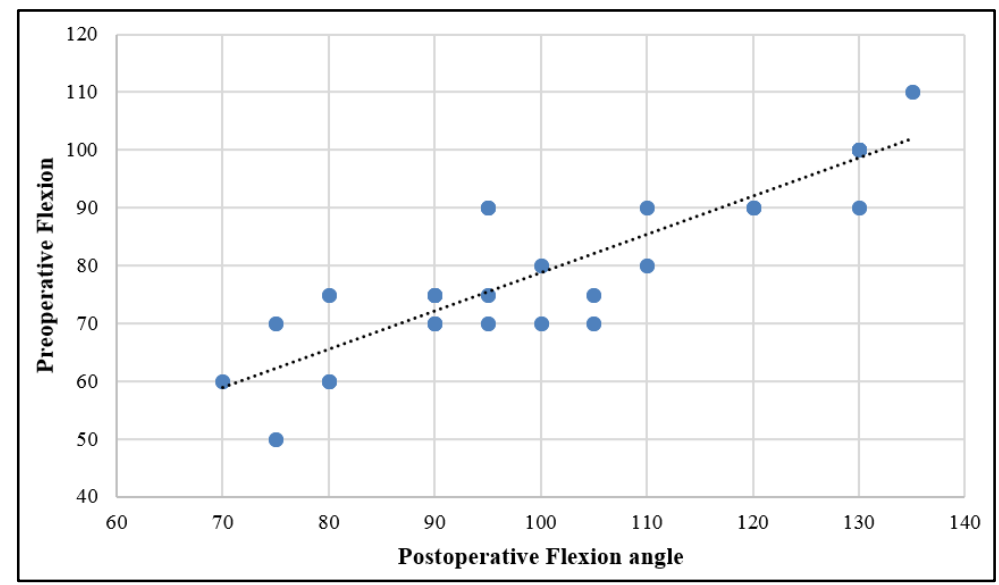

Fig. 1: Correlation between preoperative flexion and postoperative flexion angle 
Tibiofemoral Angle: The average pre operative tibiofemoral was $181.6 \pm 11.4$ and postoperatively 176.6 \pm 3.3 . The amount of flexion is statistically significant with a $\mathrm{P}$ value of $<0.001$. The pearson correlation (as data is normally distributed) is $\mathrm{R}=-0.58$ by using pearson correlation test.

Table 5: Relation between tibiofemoral angle and flexion postoperatively

\begin{tabular}{|l|c|c|c|}
\hline S. No. & Tibiofemoral angle & Flexion range & Mean flexion \\
\hline 1 & $181.6 \pm 11.4$ (pre op) & $68.2-104.3$ & 86.6 \\
\hline 2 & $176.6 \pm 3.3$ (post op) & $90.4-116.6$ & 106.7 \\
\hline
\end{tabular}

$\mathrm{P}$ value $<0.001 *$ by using Pearson correlation test * Significant

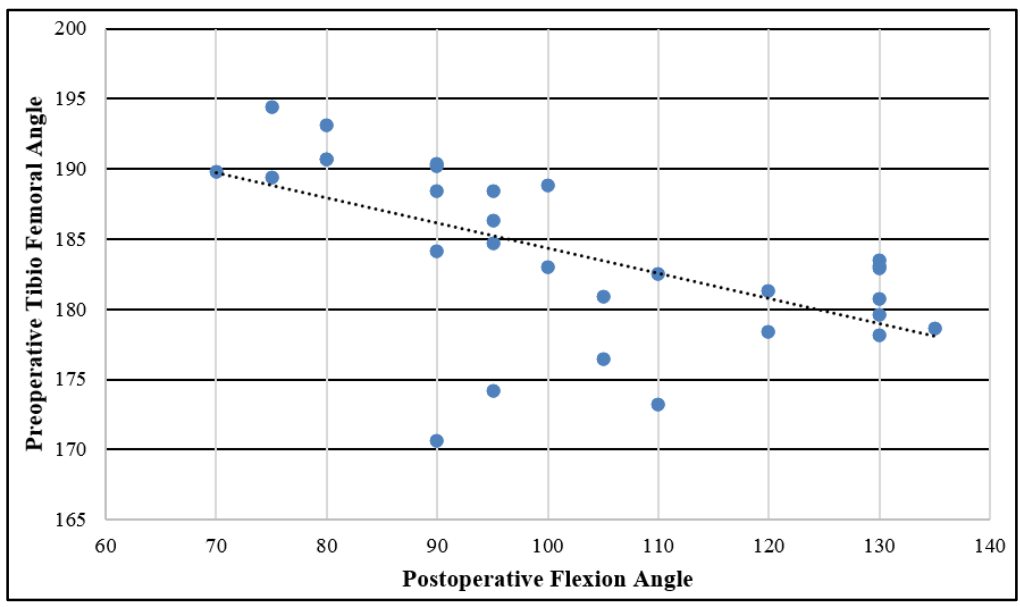

Fig. 2: Correlation between preoperative tibio femoral angle and postoperative flexion angle

\section{Discussion}

Total knee arthroplasty is a standard successful modality of treatment for various knee pathologies. The primary aim is making the patients pain free with a good range of motion. These are the parameters on which relies the patient satisfaction. This study aims at finding out factors affecting the range of motion which thus can help in predicting the flexion post operatively.

Range of Motion and Age: Patients were divided in two groups of less than and more than 60 years of age. It was found that average flexion attained in age group of more than 60 years was statistically lower than that in the less than 60 years age group. Horikawa et $\mathrm{al}^{13}$ Harvey et $\mathrm{al}^{14}$ and Anouchi et $\mathrm{al},{ }^{15}$ found no such correlation of range of motion with age. Study by Alejandero Lizaur et $\mathrm{a}^{16}$ concluded significant relation of age and range of motion.

Range of Motion and Sex: No significant correlation between range of motion post operatively and the sex of the patient is found in our study. This result co relates well with results of studies by B.S.K Reddi et al, ${ }^{17}$ Schurman et $\mathrm{al}^{7}{ }^{7}$ who concluded no significant association of flexion with sex.

Range of Motion and Body Mass Index (BMI): Range of motion and Body mass index (BMI): We found patients with lower BMI (less than 30) had significantly higher flexion attained against ones of higher BMI (higher than 30). Studies by Shoji et al, ${ }^{18}$ Lizaur et al, ${ }^{16}$ Naomi et al ${ }^{19}$ concluded significant association as well. This is important as far as counseling is concerned. Patients with higher BMI shouldn't be considered a contraindication to total knee replacement, but should be counseled about the expected range of motion postoperatively.

Range of Motion and Preop Flexion Range: Most of the studies have proved that cases with higher preoperative flexion have better range of motion post operatively. This is in agreement with results by Kurosaka et $\mathrm{al}^{20}$ who reported that preoperative range of motion of the knee joint was the most important factor governing the post operative range. However the amount of flexion increased postoperatively in cases with lower flexion pre operatively was higher than the cases with higher flexion range postoperatively. The amount of flexion increased for the group with flexion range less than 90 degrees was on an average $26.82 \%$. The flexion increased by $12.88 \%$ on an average in the group with pre operative flexion more than 90 degrees. This increased to average 101.4 degrees. But at the end the group with higher flexion pre operatively had higher range of motion postoperatively.

Range of Motion and Tibiofemoral Angle: The average pre operative tibiofemoral was $181.6 \pm 11.4$ and postoperatively $176.6 \pm 3.3$. The amount of flexion is statistically significant with a $\mathrm{P}$ value of $<0.001$. The pearson correlation (as data is normally distributed) is $\mathrm{R}=-0.58$. This negative coefficient indicates patients with higher tibiofemoral angles (varus knees) had lower post operative range of motion. However our results are contrary to the results by B.S.K Reddi et $\mathrm{al}^{17}$ who 
reported no such association. With our results its clear patients with lesser deformity have better post operative range of motion than ones who opt for surgery later, when the deformity has progressed.

There has been a discrepancy with the results of studies with some showing positive correlation with preoperative tibiofemoral varus/valgus angle on the results of postoperative flexion; ${ }^{10,12,21}$ and some concluding no such correlation. ${ }^{22,23}$

\section{Conclusion}

The primary outcome of a good total knee depends of technique, maintaining axis, balancing of soft tissues. However the patients, primarily are satisfied with good range of motion postoperatively and no pain. This study is an attempt to find factors affecting the range of motion post operatively.

1. Age (<60 years) is a factor affecting range of motion postoperatively.

2. The post operative range is independent of sex of the patient.

3. BMI $>30$ (obesity) is a cause affecting the flexion postoperatively.

4. Better range of flexion preoperatively is one of the major determinants of post operative range.

5. Tibiofemoral angle influences the range, with higher angles leading to negative impact on range of motion.

\section{References}

1. Lee K, Goodman SB. Current state and future of joint replacements in the hip and knee. Expert Rev Med Devices. 2008;5:383-93. doi:10.1586/17434440.5.3.383.

2. Anouchi YS, McShane M, Kelly F Jr, Elting J, Stiehl J. Range of motion in total knee replacement. Clin Orthop Relat Res. 1996;331:87-92. doi:10.1097/00003086199610000-00012.

3. Dennis DA, Komistek RD, Stiehl JB, Walker SA, Dennis $\mathrm{KN}$. Range of motion after total knee arthroplasty: the effect of implant design and weight bearing conditions. $J$ Arthroplasty. 1998;13:748-52. doi: 10.1016/S08835403(98)90025-0.

4. Dennis DA, Komistek RD, Hoff WA, Gabriel SM. In vivo knee kinematics derived using an inverse perspective technique. Clin Orthop Relat Res. 1996;331:107-17. doi: 10.1097/00003086199610000-00015.

5. Maloney WJ, Schurman DJ. The effects of implant design on range of motion after total knee arthroplasty. Total condylar versus posterior stabilized total condylar designs. Clin Orthop Relat Res. 1992;278:147-52.

6. Parsley BS, Engh GA, Dwyer KA. Preoperative flexion. Does it influence postoperative flexion after posteriorcruciate-retaining total knee arthroplasty? Clin Orthop Relat Res. 1992;275:204-10.

7. DJ Schurman, JN Parker and D Ornstein: total condylar knee replacement, a study of factors influencing range of motion as late as two years after arthroplasty. Journal of Bone and Joint surgery Am. 1985;67:1006-1014

8. Laubenthal KN, Smidt GL, Kettelkamp DB. A quantitative analysis of knee motion during activities of daily living. Phys Ther. 1972;52:34-43.
9. Kettelkamp DB, Johnson RJ, Smidt GL, Chao EY, Walker M. An electrogoniometric study of knee motion in normal gait. J Bone Joint Surg Am. 1970;52:775-90.

10. Schurman DJ, Matityahu A, Goodman SB, Maloney W, Woolson S, Shi H, Bloch DA. Prediction of postoperative knee flexion in Insall-Burstein II total knee arthroplasty. Clin Orthop Relat Res. 1998;353:175-84. doi:10.1097/00003086-199808000-00020.

11. Harvey IA, Barry K, Kirby SPJ, Johnson R, Elloy MA. Factors affecting the range of movement of total knee arthroplasty. J Bone Joint Surg Br. 1993;75:950-5.

12. Menke W, Schmitz B, Salm S. Range of motion after total knee arthroplasty. Arch Orthop Trauma Surg. 1992;111:280-1. doi:10.1007/BF00571524.

13. Horikawa K, Wakabayashi H, Uchida A; Factors influencing the postoperative range of motion after total knee arthroplasty. J Chubu Seisai. 2005;20(7):850-856

14. Harvey IA, Barry K, Kirby SPJ; Factors affecting the range of movement of total knee arthroplasty. J Bone Joint Surg Br. 1993;75:950.

15. Anouchi YS, McShane M, Kelly; Range of motion in total knee replacement. Clin Orthop. 1996;331:87.

16. Lizaur A, Marco L, Cebrian R; Preoperative factors influencing the range of movement after total knee arthroplasty for severe osteoarthritis. J Bone Joint Surg Br 1997; 79:629.

17. BSK Reddi, J Rai, S Suri: Study of factors influencing range of motion after total knee arthroplasty 2002;36(2).

18. Shoji H, Solomonow M, Yoshino S; Factors affecting postoperative flexion in total knee arthroplasty. Orthopedics. 1990;13:643.

19. Naomi E. Gadinsky, Jessica K. Ehrhardt, Christopher Urband, Geoffrey H. Westrich; Effect of Body Mass Index on Range of Motion and Manipulation After Total Knee Arthroplasty. The Journal of Arthroplasty. 2011;26(8):1194-1197.

20. Kurosaka M, Yoshiya S, Mizuno K. Maximizing flexion after total knee arthroplasty. J Arthroplasty. 2002;17:59.

21. Kawamura H, Bourne RB. Factors affecting range of flexion after total knee arthroplasty. J Orthop Sci. 2001;6:248-52. doi: 10.1007/s007760100043.

22. Kotani A, Yonekura A, Bourne RB. Factors Influencing Range of Motion after Contemporary Total Knee Arthroplasty. J Arthroplasty. 2005;20:850-6. doi:10.1016/j.arth.2004.12.051.

23. Li PH, Wong YC, Wai YL. Knee flexion after total knee arthroplasty. J Orthop Surg. 2007;15:149-53.

How to cite this article: Shukla $\mathrm{H}$, Goregaonkar A, Manghwani J, Rajesh S, Naskar R. Factors determing range of motion post operatively in total knee arthroplasty. Indian J Orthop Surg. 2018;4(3):245-248. 